\title{
Interactive comment on "Compound Hot-Dry and Cold-Wet Dynamical Extremes Over the Mediterranean” by Paolo De Luca et al.
}

\section{Emanuele Bevacqua (Referee)}

e.bevacqua@reading.ac.uk

Received and published: 24 April 2020

Dear De Luca et al., please, find the review at the link below.

Best regards, Emanuele Bevacqua

Please also note the supplement to this comment:

https://www.earth-syst-dynam-discuss.net/esd-2020-21/esd-2020-21-RC1-

supplement.pdf

Interactive comment on Earth Syst. Dynam. Discuss., https://doi.org/10.5194/esd-2020-21, 
Interactive comment 